\title{
Research on the New Model of Financial Report in Big Data Era
}

\author{
Juan ZHANG
}

Wuhan Business University, Wuhan, 430056, China

Email: 476251135@qq.com

Keywords: Financial Report; Big Data; New Model

\begin{abstract}
Financial report is the final product of financial accounting, an effective medium for the enterprise to communicate with the outside world about the financial condition, operating performance and development prospect and the main basis of related decision making for the financial information users. The financial report in big data era is going through severe changes. Financial report is shifting from report after the event to report in advance and from reflecting accounting information data after the event to provide enterprise with future prediction, which highlights the comprehensive feature of financial report in serving enterprise financial management and development in new time. This paper introduced the definition, features and development trend of big data era, further analyzed the development trend of financial report in big data era and its influence and requirements to financial report and discussed the 'multidimensional' characteristic in the future model of financial report, through which some ideas may be provided to the reformation, innovation and development of financial report.
\end{abstract}

\section{Introduction}

The concept of big data era originated from America when the Obama administration proclaimed its 'big data research and development plan' which means big data actually started to involve in social economic life. [1]The definition of big data in internet era is: all data innovations and developments that through the innovative framework, design and application obtain information with higher value among huge data in a more effective and economic way. Financial management and report in big data era will grow in a new model which requires that accounting and financial management personnel fully grasp the characteristics of big data era, change their own accounting management thinking and technology and promote the progress, innovation and development of accounting management and report. [2]The advent of big data era under the background of economic globalization accelerates more frequent communication and cooperation among enterprises in different districts, thus the authenticity and timeliness of financial report information are facing challenges. Under the situation of lacking effective management and disclosure of internal information, traditional financial report can't verify the corporate goodwill, strategic management, resource allocation and development plan, etc. [3] The traditional financial report model that cannot be improved far lags behind enterprise management and development and results in many financial problems. So how to promote the development of modern financial report taking the advantages of big data era and positively explore the new model of future practice has become a typical difficulty of enterprise reformation. Therefore, the study of theoretical basis and orientation of financial report reformation in new era has its profound significance. It has a prominent guiding significance and realistic value to enterprise finance.

\section{Characteristics and Development Trend of Big Data Era}

\section{A. Characteristics of Big Data Era}

The typical characteristics of big data are: the amount of data is huge from the level TB to level PB; data processing speed is fast, obeying one second law and differing from traditional data dig technique; data types are various, including voice, video, picture and geographic position, etc; the value density is low while the business value is high and there is always available data with high 
value among huge amounts of data. [4] The appearance of big data era urged people to change thought when they collect process and apply information data and such a change of thought can result in the change in behavior which is a significant power to promote social and economic development.

\section{B. Development Trend of Big Data Era}

The advent of big data era changed the traditional situation of information data which depended on sampling analysis more and can seize the characteristics and changes of data through collecting and dealing with all data in a more direct and distinct way that has increased both the quantity and level of data. Data mining in big data era does not focus on the accuracy of data processing anymore; instead, it pays more attention to the efficiency of data processing due to the various types and mixed information of big data. [5]The emphasis on data integrity and hybridity helps people close the truth of the matter and thus obtain more comprehensive data concept. In big data era, people are not keen to explore the causality of different data, instead, they emphasize more on how to take the advantage of the data to gain more valuable information which can catch and predict future. The new idea of big data era brought new change in modern financial accounting management, leading to the reformation of financial management in new views, new ways and new technology, etc. The working pattern of accounting and audit staffing both will go through new changes and the management responsibility financial report takes on will be more important, which has important significance for the innovation of modern financial management model.

\section{Contents of Financial Report Model}

The traditional definition of financial report is 'the structural expression of the financial position, operating results and cash flows of enterprise'. Financial report should include the following parts at least: (1) the balance sheet; (2) income statement ;(3) statement of cash flows; (4) statement of changes in owner's equity (or shareholders' equity). In such a definition, the model of financial report only includes two fundamental elements, that is the content and structure of financial report, however, in fact, the elements that financial report model should include are far more than this and a 'model' can be called only when all related elements of financial report are contained. So this article extended the concept of financial report model. Financial report model not only includes the content and structure of it, but contains methods, means and tools of realization, including the whole financial information supply chain from the provider to the user of financial report, namely, the content, structure and the distribution, transmission and use of information. It can be said that a financial report model is a set of process of the production and use of financial information.

\section{Analysis of Big Data Era's Effects on Financial Report}

The emergence of modern information technology brought huge reformation of financial report model, fundamentally changing each part of supply chain of financial report. [6]It can be said that the evolution of information technology directly promoted the development of financial report model and is the foundation of realizing modern financial report model.

A. Technical Support of Big Data to Financial Report Content

The development of information technology highly improved the ability of data processing and the content of financial report model has been extended. Including goodwill, patents, franchises, copyright, etc., intangible asset that could not get rational recognition and measurement in traditional financial report model based on tangible asset can be included in financial report model and financial report has the ability to provide information that users need to evaluate and measure investment risk as well.

The financial report model under the background of big data contains various contents as follows:

a. Financial and non-financial data, including financial statements and related information disclosure and high-level operating data and performance indicators and so on that managers use for enterprise management. 
b. The enterprise management's analysis of financial and non-financial data.

c. Forward-looking information, including the opportunities and risks, business plan of management, comparison between the actual performance and the past plan.

d. Related information of enterprise managers and shareholders.

e. Background information, including strategic planning, industrial structure, economic environment, etc.

In a nutshell, big data expanded the information content of financial report, and the historic, quantitative financial information that traditional financial report model disclosed extended into qualitative information, forward-looking information and non-financial information.

B. Technical Support of Big Data to the Generation and Transmission of Financial Report

Traditional financial report used paper as media, but under the background of big data, with the progress of computer storage technology, disk and CD-Rom has gradually become a new carrier of financial report. And the transmission of financial report has changed into an electronic way accordingly. In theory, the change of data carrier and transmission way fundamentally eliminate many classification parts of information processing since the same one basic data can realize multidimensional restructuring of information. The development of computer network brought network carrier for financial report and reduced time lag among the generation, spread and usage of financial information, making their relations closer. Information technology makes the financial report stronger efficiency, bigger volume and surface, besides, the cost is greatly reduced. Because of the low error rate of computer processing, the strict accordance with the procedures for data processing guaranteed the quality of financial information authenticity, integrity, fairness, openness and improved normatively of information disclosure, which is conducive to curb the phenomenon of accounting information distortion, reduce the monopoly on information, manipulation and gradually eliminate the shady phenomenon caused by delayed information disclosure and information asymmetry.

\section{The Analysis of Financial Report Model in Big Data Era}

\section{A. Multidimensional Characteristics}

From the perspective of current big data technology development and application trends, the developing model of financial report more will highlight the 'multi-dimensional' characteristics. Multidimensional accounting integrates advantages of modern accounting management theories such as the balanced scorecard, operation costing and triple-entry accounting, relying on the Internet and information technology completes the record of value activities of enterprise management, with business form as the core, relying on large data support, forms business entries including cash flow, accounting entry flow and management flow and effectively mixes non-financial indicators such as human resources, enterprise management, internal control, customer service, etc. so as to build up the multidimensional information service system that releases instant financial report, which highlights the sharing value and strategic value of data information in big data model. Under the big data era, the application and development of the multidimensional accounting report represents the boundary revolution in the field of enterprise financial management. [7] Such a new report model that changed depth and breadth of financial report object changed the evaluation and influence of enterprise value. And under such a change, the prediction of enterprise dynamic operating earnings becomes possible, and taking the advantages of information disclosure like third-party data analysis with the company's management announced by enterprise board to get key data information of enterprise management, there are more possibilities to explore enterprise potential strategic value. It can be said that the application of multidimensional financial report model promoted the integration of management accounting and financial accounting, providing a strong support for the enterprise to set the optimal development strategy, avoid major operational risk and implement optimal decision .

B. Multidimensional Financial Report System

The design core of multidimensional financial report system is enterprise value activities. Assuming that an enterprise has three important businesses in the near future in a given area, and 
the analysis of multidimensional entry tables, comprehensive income statement and treasure table of the three business can intuitively show the applications and advantages of multidimensional financial report centered by enterprise value activities. If the three most important businesses separately are enterprise financing, enterprise production inventory cost management and income management, these value activities all belong to the category of business activity, and the description of the movement process of above value activities will apply multidimensional concept. Multidimensional financial report integrates a variety of accounting flow and measurement attribution and represents it in each multidimensional business entries and thus provides enterprise management, investment and other relevant department's reliable decision support. For example, if corporate finance takes into consideration the history of their own self-built fixed assets cost and commercial value, based on the financial report, the board of directors of the enterprise can make decision whether it is for private use or rental. If enterprise production inventory cost management considered the change of market effect for raw material price fluctuations, their market share and the change of the shipments, based on the financial report, the enterprise can decide whether to increase or cut production.

\section{Conclusion}

With the popularization of information technology and the development of network economy, the traditional financial report model is facing serious challenges. How to build a financial report model that can adapt to the information technology condition has become a hot issue discussed by both accounting theory and practice realms, so it has both theoretical and practical significance. Financial report in the era of big data ushered in new changes. The development of the financial report has both advantages and disadvantages under the influence of big data era. We should correctly grasp the characteristics of big data actively applying new thinking, new technology and new methods in the new development environment, perform forward-looking and strategic role of financial report in financial management more, provide sufficient potential for development of enterprises and promote the innovation of the financial accounting and management in the new period. Multidimensional information accounting service, as a typical characteristic of financial report in the future development, promoted the integration of management accounting and financial accounting and provides a strong support for enterprises to set optimal development strategy, avoid major operational risk and make the optimal decision, which is advantageous to fully play the application value of enterprise financial report in the era of big data.

\section{References}

[1] On the Construction of a Multi-Stage, Multi-Person Business Game. Richard Bellman,Charles E. Clark,Donald G. Malcolm,Clifford J. Craft,Franc M. Ricciar. Operations Research. 1957

[2] Continuous auditing with a multi-agent system[J] . Charles Ling-yu Chou,Timon Du,Vincent S. Lai. Decision Support Systems . 2006 (4)

[3] Clarifying business models: origins, present, and future of the concept. Osterwalder A,Yves Pigneur,Chirstopher L Tucci. Communications of the Association for Information Systems. 2005

[4] The acceptance and adoption of continuous auditing by internal auditors: A micro analysis[J] . Miklos A. Vasarhelyi,Michael Alles,Siripan Kuenkaikaew,James Littley. International Journal of Accounting Information Systems. 2012 (3)

[5] Earnings, book values, and dividends in equity valuation. Ohlson James A. Contemporary Accounting Research. 1995

[6] Business Models, Business Strategy and Innovation[J] . David J. Teece. Long Range Planning. $2009(2$

[7]Economic Action and Social Structure: The Problem of Embeddedness. Granovetter M. The American Journal of Sociology. 1985 